\title{
Structural, Surface, Thermal and Catalytic Properties of Chitosan Supported Cu(II) Mixed Ligand Complex Materials
}

\author{
R. Antony ${ }^{1}$, S. Theodore David ${ }^{1 *}$, K. Karuppasamy ${ }^{1}$, K. Saravanan ${ }^{2}$, S. Thanikaikarasan ${ }^{1}$, \\ S. Balakumar ${ }^{1}$ \\ ${ }^{1}$ Centre for Scientific and Applied Research, School of Basic Engineering and Sciences, PSN College of Engineering and Technol- \\ ogy, Tirunelveli, India; ${ }^{2}$ Discipline of Inorganic Materials and Catalysis, Council of Scientific and Industrial research, Central Salt \\ and Marine Chemicals Research Institute, Bhavnagar, India. \\ Email: ${ }^{*}$ s.theodore.david@gmail.com
}

Received June $9^{\text {th }}, 2012$; revised July $13^{\text {th }}, 2012$; accepted July $26^{\text {th }}, 2012$

\begin{abstract}
Schiff base modified chitosan (SC: salicylidenechitosan) has been synthesized by the condensation reaction of chitosan and salicylaldehyde. From this ligand, three $\mathrm{Cu}$ (II) mixed ligand complexes [Cu (SC) (SA)] (1), [Cu (SC) (ST)] (2) and [Cu (SC) (VA)] (3) (SA: salicyledeneaniline; ST: salicylidenethiourea; VA: $o$-vanillideneaniline) have been synthesized successfully. The structure and properties of the complexes have been characterized by spectral and analytical techniques. Their thermal and morphological properties have been also discussed in detail. The crystallinity of the compounds has explored with X-ray diffraction spectroscopy. The catalytic ability of the complexes has been investigated in the oxidation reaction of cyclohexane into cyclohexanol and cyclohexanone using hydrogen peroxide as oxidant and their catalytic activity is in the order of complex $1>2<3$.
\end{abstract}

Keywords: Chitosan; Scanning Electron Microscopy; Active Site; Heterogeneous Catalysts

\section{Introduction}

Chitosan is a cationic amino polysaccharide, copolymer of glucosamine and N-acetyl glucosamine, obtained by the alkaline, partial N-deacetylation of chitin which is the most important and abundant polysaccharide after cellulose isolated from different natural sources predominantly marine, such as the shells of crustaceans, squid pen and krill. It is also found in the exoskeleton of insects and in the cell walls of fungi [1-4]. Chitosan dissolves in aqueous solution of organic acids as acetic, formic, citric; besides inorganic acids, as diluted hydrochloric acid resulting in viscous solutions. This biopolymer, due to its unique physiochemical properties and biological activities has the number of applications ranging from cosmetics, artificial skin, photography, food and nutrition, ophthalmology and waste water treatment $[5,6]$. The free amino group available in the chitosan structure enables a variety of chemical modifications and substitution processes like carboxylation, acylation, sulfation, Schiff's base formation, enzymatic substitution, metal chelation, cyanoethylation, nitration, phosphorylation, etc. [7-9]. The reaction of this free amino group with al-

*Corresponding author. dehydes and ketones resulting in the formation of Schiff bases which are often reported for the reason that they offer opportunities for inducing biological activity, adsorption of metal ions and the support of metal complex catalysts[10-13]. The insertion of functional groups into the chitosan polymer matrix may improve its capacity of interaction with metallic ion by complexation. Chitosan anchored Schiff base complexes have been amongst the most widely studied coordination compounds in the past few years, since they are becoming increasingly important as biochemical, antimicrobial and catalytic reagents. There are some reports available with transition metal complexes obtained from Schiff base modified chitosan $[14,15]$.

The oxidation of organic compounds with an eco friendly oxidant, aqueous hydrogen peroxide, is a challenging goal of catalytic chemistry. In specific, the research on the oxidation of cyclohexane captures special attention because its oxidized products are of immense industrial importance, significantly in the manufacture of adipic acid which is again a raw material of nylon 6, 6', detergents, rubber chemicals, pesticides etc [16-18]. Due to the inherent advantages of heterogeneous catalysis over homogeneous catalysis, a great deal of efforts has 
been devoted to the development of heterogeneous catalysts. By making the use of the chelating ability of chitosan with metal ion, researchers have studied a new catalyst with more catalytic activity and reusable features. Many studies indicate that the copper complexes derived from chitosan anchored Schiff base acts as good heterogeneous catalysts in oxidation reactions $[19,20]$.

Bearing these facts in our mind, herein we report the synthesis and characterization of the $\mathrm{Cu}$ (II) mixed ligand complexes holding a Schiff base (Figure 1(a)), salicylidenechitosan (SC) derived from chitosan and salicylaldehyde. Here, our aim is to establish a comparative study of the catalytic effectiveness of the complexes in the oxidation reactions of cyclohexane.

\section{Experimental Section}

Chitosan powder of medium molecular weight was purchased from Hi media chemical company. The purification was carried out by the dissolution of commercial chitosan powder (approximately $2.5 \mathrm{~g}$ ) in 1 litre of dilute $0.5 \mathrm{molL}^{-1}$ acetic acid solution. All other chemicals and solvents were obtained from Merck and used as received. All manipulations were completed under aerobic conditions.

\subsection{Characterisation Techniques}

A Carlo Erba 1108 model elemental analyzer was used to collect the micro analytical data $(\mathrm{C}, \mathrm{H}$ and $\mathrm{N})$ and compared with the calculated theoretical values. Copper content of complexes was estimated gravimetrically as its oxide [21]. The FT-IR spectra of the complexes were recorded on a Jasco FT-IR/4100 spectrophotometer with $4 \mathrm{~cm}^{-1}$ resolution in the range of 4000 to $400 \mathrm{~cm}^{-1}$. Electronic absorption spectral studies were carried out in DMSO using a Shimadzu UV - 1601 spectrophotometer in the range of $200-800 \mathrm{~nm} .{ }^{1} \mathrm{H}$ NMR spectra of SC was computed on a Bruker Avance 300 FT-NMR spectrometer in $1 \% \mathrm{HCl} / \mathrm{D}_{2} \mathrm{O}$ solution. The magnetic susceptibility values of the complexes were measured on a modified Hertz SG8-5HJ model Gouy type magnetic balance. Room temperature molar conductance measurements of $10^{-3}$ solutions of the complexes in DMSO were analyzed with a deep vision model 601 digital direct reading deluxe conductivity meter. Thermal properties (from thermo gravimetric (TG) and differential thermal (DTA) analyses) were investigated on a Mettler Toledo star system in the temperature range of $30^{\circ} \mathrm{C}-800^{\circ} \mathrm{C}$ with heating rate of $10^{\circ} \mathrm{C} \mathrm{m^{-1 }}$ under $\mathrm{N}_{2}$ flow. Surface morphology of the synthesized products was studied with the use of scanning electron microscope of model SEM-JSM 6390 with accelerating voltage of $20 \mathrm{kV}$ at liquid $\mathrm{N}_{2}$ temperature. X-ray powder diffraction determinations were made using an X-ray diffractometer (XPERT PRO
PANalytical, Netherland) for phase identification. The patterns were run with $\mathrm{CuK}_{\alpha}$ radiation $(\lambda=0.1545 \mathrm{~nm})$ with a generator at $40 \mathrm{kV}$ and $30 \mathrm{~mA}$.

\subsection{Synthesis of Ligands and Complexes}

$\mathrm{SC}$ was synthesized according to the following procedure. Chitosan $(10 \mathrm{mmol})$ was magnetically stirred in ethanol for $5 \mathrm{hrs}$ and to this pre-treated ethanolic chitosan suspension, salicylaldehyde $(10 \mathrm{mmol})$ was added and the mixture was refluxed for $24 \mathrm{hrs}$. After cooling, the yellow colour solid was separated by filtration, washed with ethanol and ether and then dried at $50^{\circ} \mathrm{C}$ under vacuum for $12 \mathrm{hrs}$.

A mixture of salicylaldehyde $(0.1 \mathrm{~mol})$, aniline $(0.1$ mol) and ethanol was refluxed for the synthesis of salicyledeneaniline (SA). The resultant mixture was cooled, filtered off washed with hot water and dried in vacuum. Salicylidenethiourea (ST) from salicylaldehyde and thiourea and $o$-vanillideneaniline (VA) from o-vanillin and aniline were derived by repeating the similar procedure.

For the preparation of complex 1 (Figure 1(b)), at first ethanolic solution of SC $(0.75 \mathrm{mmol})$ was stirred for 5 hrs in a flask equipped with a magnetic stirrer. Then, SA $(0.75 \mathrm{mmol})$ and $\mathrm{Cu}\left(\mathrm{CH}_{3} \mathrm{COO}\right)_{2}(0.75 \mathrm{mmol})$ were added to this pre-treated SC suspension and it was refluxed for 12 hrs with magnetic stirring. Complex 2 was synthesized by refluxing the pre-treated SC with ST and $\mathrm{Cu}\left(\mathrm{CH}_{3} \mathrm{COO}\right)_{2}$. Complex 3 was synthesized by refluxing the pre-treated $\mathrm{SC}$ with $\mathrm{VA}$ and $\mathrm{Cu}\left(\mathrm{CH}_{3} \mathrm{COO}\right)_{2}$. In all the cases, the final precipitate was filtered off, washed with ethanol and ether and dried in vacuum.

\subsection{Catalytic Oxidation Procedure}

The oxidation of cyclohexane was performed in an aerobic condition. Typically, $10 \mathrm{mmol} 30 \%$ hydrogen peroxide solution was added to the copper complex $(0.05 \mathrm{~g})$ in $10 \mathrm{ml}$ of acetonitrile in a $25 \mathrm{ml}$ flask equipped with a magnetic stirrer. To this $5 \mathrm{mmol}$ of organic substrate was
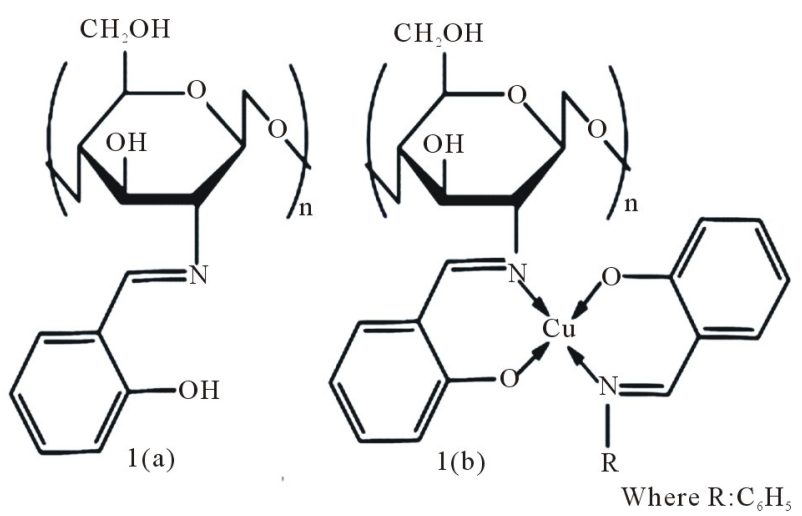

Figure 1. Structure of SC (a); and complex 1 (b). 
added. The reaction mixture was stirred at room temperature and $70^{\circ} \mathrm{C}$ under atmospheric pressure conditions. After $8 \mathrm{~h}$, the mixture was filtered, concentrated and collected. A blank experiment for the oxidation of cyclohexane was carried out without the copper complex keeping the other experimental conditions unaltered. The collected product samples were analyzed with a Hewlett-Packard gas chromatogram (HP 6890) having FID detector. From the resulting chromatographs, the identification of the products and the selectivity of the products also were attained. The reusability of the complexes was proved with the complex 1 by repeating continuously five catalytic runs keeping the same catalyst again and again after successive purification.

\section{Results and Discussion}

\subsection{Degree of Substitution (DS) of SC}

The micro analytical data $(\mathrm{C}, \mathrm{N})$ obtained from elemental analysis is used to find out the degree of substitution (DS) of SC. From Table 1, C/N ratio of chitosan and its Schiff base ligand, SC are calculated as 5.22 and 11.15 , respectively.

The DS of the ligand, $\mathrm{SC}$ to- $\mathrm{NH}_{2}$ group on chitosan is calculated by the Equation (1).

$$
D S=\frac{a(C / N)_{m}-(C / N)_{o}}{n}
$$

where $(C / N)_{m}$ is the $\mathrm{C} / \mathrm{N}$ ratio of modified chitosan, $\mathrm{SC},(C / N)$ is the $\mathrm{C} / \mathrm{N}$ ratio of original chitosan and " $a$ " and " $n$ " are the number of nitrogen and carbon introduced after Schiff base modification, respectively. The DS calculated for chitosan is 0.46 .

\subsection{Structural Properties}

FT IR spectra of chitosan and SC are shown in Figures 2(a) and 2(b), respectively. The IR spectrum of chitosan exhibits strong peak at $3359 \mathrm{~cm}^{-1}$ which can be assigned to the axial vibration of $\mathrm{O}-\mathrm{H}$. It is superimposed to the
$\mathrm{N}-\mathrm{H}$ stretching band and inter hydrogen bands of the polysaccharide. The $\mathrm{C}-\mathrm{H}$ axial stretching band arises at $2878.24 \mathrm{~cm}^{-1}$. The other important observed characteristic bands of chitosan are, bands due to the $-\mathrm{NHCOCH}_{3}$ (acetyl) units (with $\mathrm{C}=\mathrm{O}$ stretching) at $1651.98 \mathrm{~cm}^{-1}$, (with $\mathrm{N}-\mathrm{H}$ bending) at $1580.38 \mathrm{~cm}^{-1}$, (with C-N stretching coupled with $\mathrm{N}-\mathrm{H}$ plane deformation) at 1419.07 $\mathrm{cm}^{-1}$ and (symmetrical angular deformation of $\mathrm{CH}_{3}$ ) at $1375.96 \mathrm{~cm}^{-1}$; C-N amino groups axial deformation at $1322.59 \mathrm{~cm}^{-1}$; C-O-C stretching vibration at 1027.87 $\mathrm{cm}^{-1}$; and the specific bands of the $\beta(1-4)$ glycosidic bridge at 1149.37 and $895.77 \mathrm{~cm}^{-1}[22,23]$. In the FT IR spectrum of $\mathrm{SC}$, there is no evidence for carbonyl stretching which is a characteristic band of salicylaldehyde at around $1720 \mathrm{~cm}^{-1}$, the axial vibration of $\mathrm{O}-\mathrm{H}$ is arrived at $\mathrm{cm}^{-1}$, the $\mathrm{C}-\mathrm{H}$ stretching frequency appears at 2 $893.66 \mathrm{~cm}^{-1}$, the significant characteristic $\beta(1-4)$ glycosidic bridge bands Ccur at 1149.37 and $895.77 \mathrm{~cm}^{-1}$ and a new important band arrived at $1624.73 \mathrm{~cm}^{-1}$ which is a characteristic stretching frequency of azomethine group $(\mathrm{CH}=\mathrm{N})$ of SC. FT IR spectra of the complexes 1,2 and 3 (Figures 2(c)-(e), respectively) show the similar spectra like SC with some changes. The $\mathrm{C}=\mathrm{N}$ stretching band is shifted to the lower frequency in all the complexes $\left(1602 \mathrm{~cm}^{-1}\right.$ (1), $1613.16 \mathrm{~cm}^{-1}$ (2) and 1596.77 $\mathrm{cm}^{-1}$ (3)) due to the coordination of $\mathrm{Cu}(\mathrm{II})$ metal centre with azomethine nitrogen atom [24]. Figure 2(d) exhibits the bands at 773.02 and $1393.32 \mathrm{~cm}^{-1}$ which are attributed to the coordination of sulfur atom of thiourea with $\mathrm{Cu}(\mathrm{II})$ ion.

Electronic spectral studies of the transition metal complexes are generally used to confirm their geometry around the central metal ion. The nature of geometry around this central transition metal ion is further supported and confirmed by the magnetic susceptibility and molar conductance studies which also help to prove the stoichiometry and formation of the complexes.

$\mathrm{UV}-\mathrm{V}$ is spectra of SC, complex 1, 2 and 3 are given in Figures 3(a)-(d), respectively. The UV-Vis spectrum of

Table 1. Physical characterization, micro analytical data $(\mathrm{C}, \mathrm{H}$ and $\mathrm{N})$ of the complexes.

\begin{tabular}{|c|c|c|c|c|c|c|c|c|c|c|}
\hline \multirow{3}{*}{ Compound } & \multicolumn{8}{|c|}{ Elemental and metal analysis data } & \multirow{3}{*}{$\begin{array}{c}\text { Molar } \\
\text { conductivity }\left(\lambda_{m}\right) \\
\left(\Omega^{-1} \mathrm{~cm}^{2} \mathrm{~mol}^{-1}\right)\end{array}$} & \multirow{3}{*}{$\begin{array}{c}\text { Magnetic } \\
\text { susceptibility }\left(\mu_{e f f}\right) \\
(\mathrm{BM})\end{array}$} \\
\hline & \multicolumn{4}{|c|}{ Calculated (\%) } & \multicolumn{4}{|c|}{ Found (\%) } & & \\
\hline & $\mathrm{C}$ & $\mathrm{H}$ & $\mathrm{N}$ & $\mathrm{Cu}$ & $\mathrm{C}$ & $\mathrm{H}$ & $\mathrm{N}$ & $\mathrm{Cu}$ & & \\
\hline Chitosan & 44.72 & 6.88 & 8.69 & & 44.35 & 6.51 & 8.49 & & & \\
\hline Complex 1 & 59.59 & 4.62 & 5.35 & 12.13 & 59.08 & 4.30 & 5.08 & 12.01 & 11 & 1.70 \\
\hline Complex 2 & 49.75 & 4.17 & 8.29 & 12.53 & 49.37 & 3.98 & 8.16 & 12.14 & 15 & 1.93 \\
\hline Complex 3 & 58.53 & 4.73 & 5.06 & 11.47 & 58.05 & 4.46 & 4.87 & 10.98 & 17 & 1.72 \\
\hline
\end{tabular}




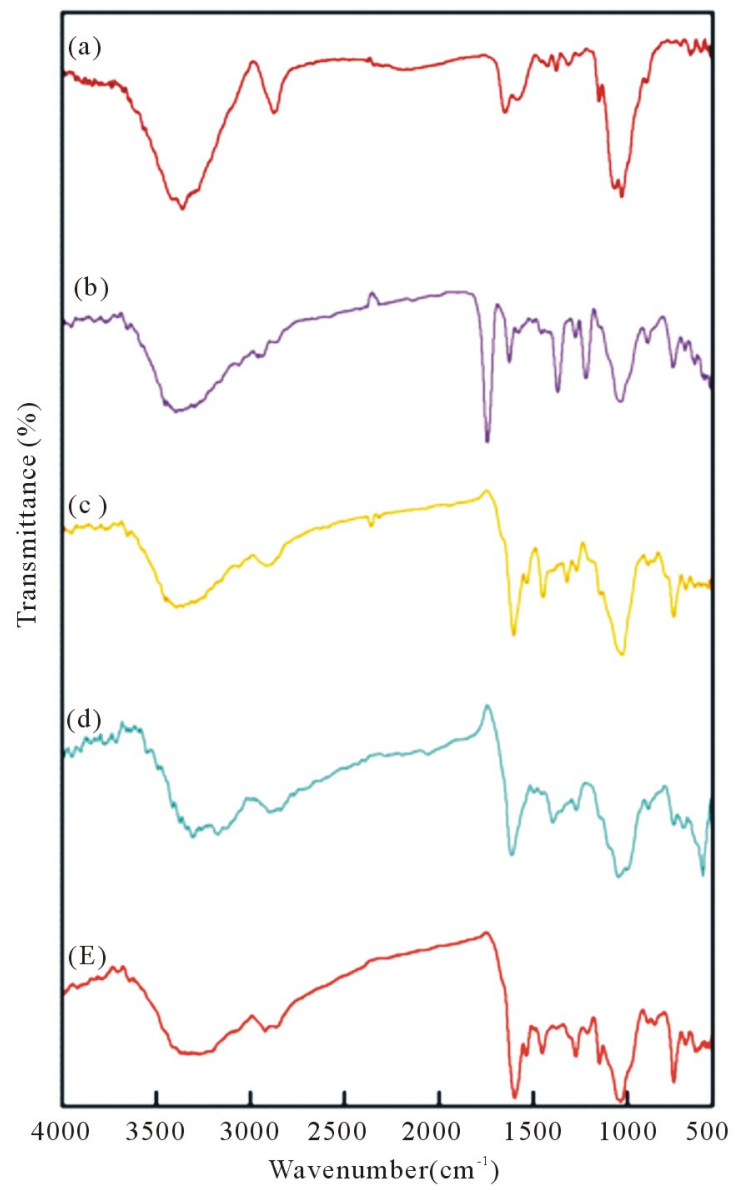

Figure 2. FT-IR spectra of chitosan (a); SC (b); complex 1 (c); complex 2 (d); and complex 3 (e).

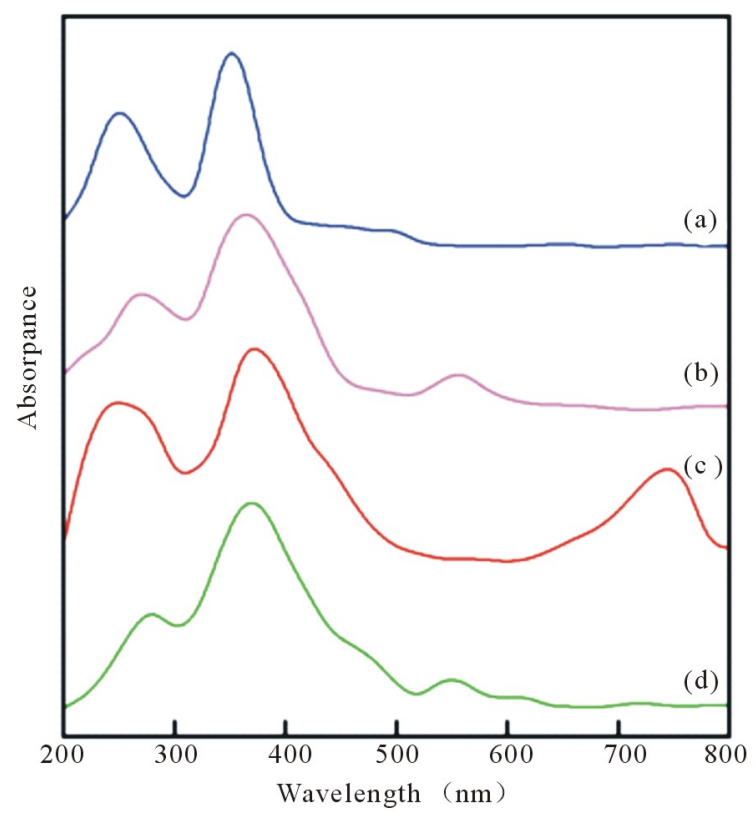

Figure 3. UV-Vis. Spectra SC (a); complex 1 (b); complex 2 (c); and complex 3 (d). free SC shows strong absorption bands at the range 235 $255 \mathrm{~nm}$ which could be assigned to $\pi-\pi^{*}$ and $n-\pi^{*}$ transitions in the aromatic ring or azomethine $(-\mathrm{C}=\mathrm{N})$ [25]. These absorption bands differ in intensities and in the UV-Vis spectra of the complexes 1, 2 and 3. More than this, the slight shift in the wavelength is also noted. These changes may be due to the coordination of azomethine nitrogen and phenolic oxygen of SC to the $\mathrm{Cu}$ (II) ion. In addition, all the complexes exhibit a new band arising from their characteritic d-d transition which explains the nature of the geometry of the complexes. This characteristic band appeared at $540-560 \mathrm{~nm}$ for the complexes, 1 and 3 . It corresponds to the ${ }^{2} \mathrm{~B}_{1 \mathrm{~g}} \rightarrow{ }^{2} \mathrm{~A}_{1 \mathrm{~g}}$ transition and makes a confirmation to assign the tetra coordinated $\left(\mathrm{N}_{2} \mathrm{O}_{2}\right)$ square planar geometry for these two complexes, 1 and 3 [26]. But for the complex 2, this significant band appeared at the higher wavelength range (735 - $755 \mathrm{~nm}$ ) for the complex 2. It clearly supports the penta coordinated $\left(\mathrm{N}_{2} \mathrm{O}_{2} \mathrm{~S}\right)$ square pyramidal geometry to the complex 2 .

Table 1 also shows the magnetic moment and molar conductance values of complexes. The magnetic moment values measured at room temperature for the complexes 1,2 and 3 are 1.70, 1.93 and 1.72 BM, respectively. These values consent with the spin only magnetic moment of $\mathrm{S}=1 / 2, \mathrm{~d}^{9} \mathrm{Cu}(\mathrm{II})$ system and also support the square planar geometry to the complexes 1 and 3 and square pyramidal geometry to complex 2 . The molar conductance values of $10^{-3} \mathrm{M}$ solution of complexes are in the range of $11-17 \mathrm{ohm}^{-1} \mathrm{~cm}^{2} \mathrm{~mol}^{-1}$. These values assign the very expected non-electrolyte nature to all the studied complexes.

${ }^{1} \mathrm{H}$ NMR spectroscopy is a powerful technique used to investigate the proton environment of organic molecule. In ${ }^{1} \mathrm{H}$ NMR spectral study, the chemical shifts observed for SC are: $2.4 \mathrm{ppm}$ (acetyl proton of chitosan), $3.9 \mathrm{ppm}$ (C2 proton), and 4.2 - 4.77 ppm (C3, C4, C5 and C6 protons). The chemical shift at $9.8 \mathrm{ppm}$ (azomethine proton) confirms the formation of Schiff base SC. It is further confirmed by the multiplets between $6.7-8.1$ ppm (aromatic protons).

\subsection{Thermal Properties}

TG-DTA study is used to explain thermal stability and mode of decomposition of SC and complexes. The TG curves of SC and complexes show two mass loss stages. The first one might be due to the elimination of physically adsorbed water molecules. And the second one with endothermic decomposition could be the decomposition of polymer matrix. The thermal stability of the ligand, $\mathrm{SC}$ is greater than that of its complexes which may be due to the change in stacking order of ligand, SC after the complex formation with $\mathrm{Cu}$ (II). 


\subsection{Surface Morphology}

Scanning electron microscopy is a fundamental tool to predict surface morphology and particle sizes of materials. The morphology and the distribution of particle sizes of the compounds are explained as illustrated in Figure 4. Figure 4(a) exhibits smooth and regular surface morphology with particle sizes of greater than $10 \mu \mathrm{m}$. Schiff base, SC reveals irregular surface with small particle sizes of less than $10 \mu \mathrm{m}$ as shown in Figure 4(b). These surface morphology changes accompanied with decrease in particle sizes for SC could be obtained from the chemical modification of chitosan $[6,27,28]$. The decrease in the particle sizes after the formation of SC resulting from the Schiff base modification could enhance adsorption capacity of the metal ions through complex formation [28,29]. However, the interaction between chitosan and salicylaldehyde surmounts the reduction of particle sizes by reducing the number of free amino groups available on the surface of the chitosan [28]. Figure 4(c) describes completely different surface morphology accompanied with pores and roughness for the complex1. The particle sizes of complex 1 are significantly less than that of both chitosan and SC. The appearance of pores on surface of complex 1 proves that the imprinting of the copper ions on SC could leave their footprints which increase the number of pores in the surface. This behavior may be attributed to the coordination of copper ion to the active sites of the ligand [30]. The pores and roughness emerged on surface of these chitosan supported complexes can able to act as active sites in heterogeneous catalytic reactions.

\subsection{Crystalline Properties}

A significant intermolecular hydrogen bond leads to the crystalline character of chitosan that distinguishes it from most other carbohydrate polymers [31]. It is evidenced from the diffraction pattern of chitosan (Figure 5(a)) which exhibits its characteristic peak at $2 \theta=20^{\circ}$ in accordance with the previous reports $[12,13,32,33]$. The XRD pattern of the Schiff base, SC (Figure 5(b)) shows two peaks at $2 \theta=14^{\circ}$ and $20.1^{\circ}$. The peak at $20.1^{\circ}$ is slightly wider than that of the free chitosan which suggests the decrease in crystallinity after the grafting of salicylaldehyde in the backbone of chitosan structure. This notable characteristic peak is much wider than that of the ligand (SC) and chitosan. Figures 5(c)-(e) are XRD patterns of all the complexes which show the non existence of the characteristic peaks for pure copper. This observation concludes that the basic structure of the chitosan was not disturbed in the whole process of the complex preparation.

Moreover, the crystallinity of all the analyzed compounds was calculated as following the previous reports

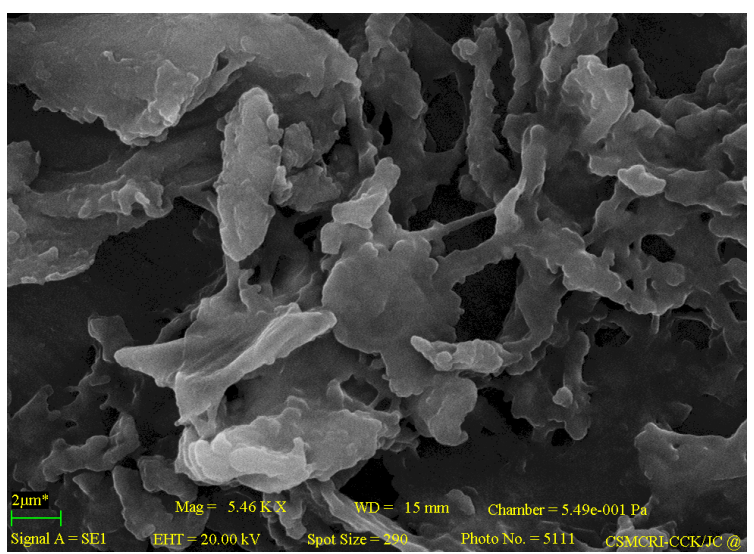

(a)

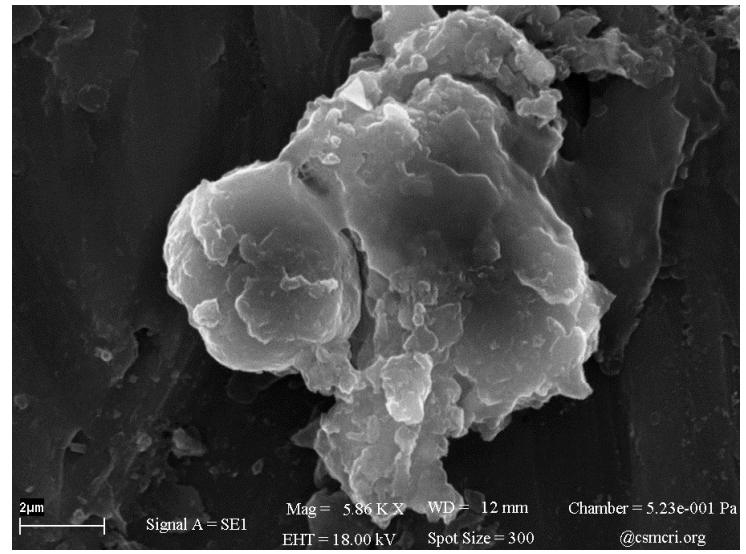

(b)

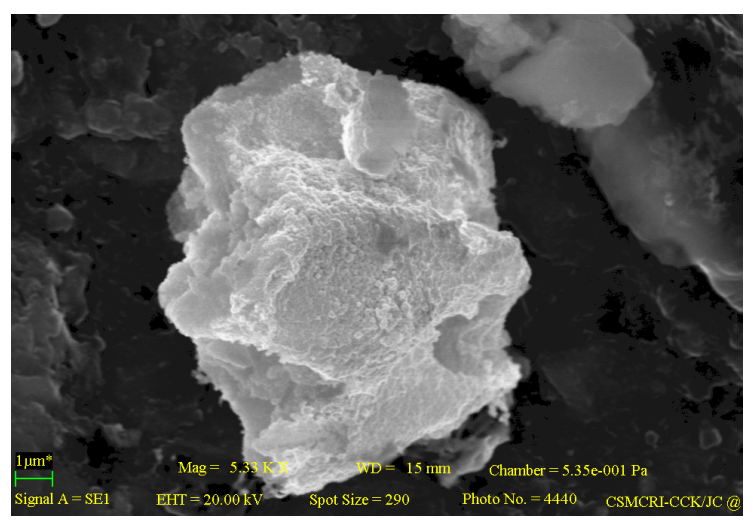

(c)

Figure 4. Scanning electron microscopes of chitosan (a); SC (b); and complex 1 (c).

$[33,34]$. The crystallinity of the compounds can be related on the basis of the parameter, crystalline index. The crystalline index is calculated as follows using Equation (2):

$$
\text { CrystallineIndex }(\%)=\frac{I_{110}-I_{a m}}{I_{110}} \times 100
$$

where $I_{110}$ is the maximum intensity at $\sim 20^{\circ}$ and $I_{a m}$ is the intensity of amorphous diffraction at $16^{\circ}$. Table 2 explicates 
Table 2. $2 \theta$ values, $d$ spacing and crystalline index of the complexes.

\begin{tabular}{|c|c|c|c|c|c|}
\hline \multirow{2}{*}{ Compound } & \multirow{2}{*}{\multicolumn{3}{|c|}{$\begin{array}{c}2 \text { Theta (degree) } \\
(\mathrm{d} \text { spacer value }(\mathrm{nm}))\end{array}$}} & \multicolumn{2}{|c|}{ Crystalline index } \\
\hline & & & & $\%$ & Error $( \pm)$ \\
\hline Chitosan & & & $20(0.444)$ & 47.31 & 2.3655 \\
\hline $\mathrm{SC}$ & & $14(0.639)$ & $20.1(0.441)$ & 42.19 & 2.1095 \\
\hline Complex 1 & $13.4(0.662)$ & $18.4(0.482)$ & $19.3(0.460)$ & 39.07 & 1.9535 \\
\hline Complex 2 & - & $14(0.648)$ & $20.3(0.437)$ & 41.70 & 2.0850 \\
\hline Complex 3 & - & $14.1(0.637)$ & $20(0.436)$ & 31.17 & 1.5585 \\
\hline
\end{tabular}

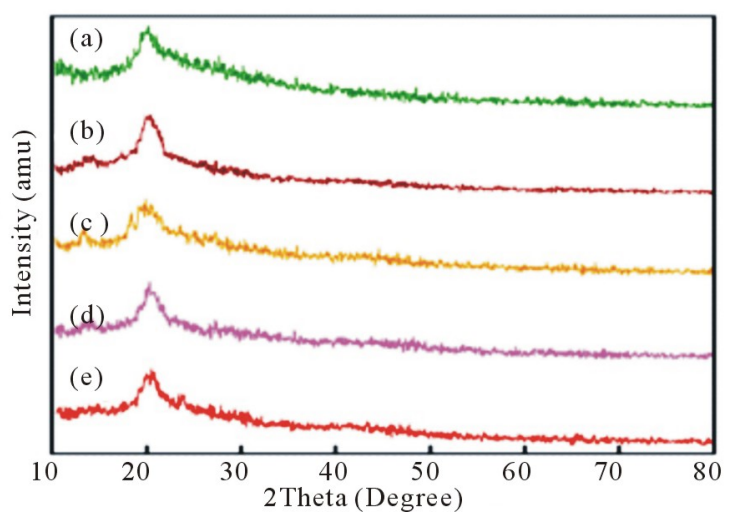

Figure 5. XRD patterns of chitosan (a); SC (b); complex 1 (c); complex 2 (d); and complex 3 (e).

$2 \theta$, d-space and calculated crystal index values for all compounds. The variation of crystalline index for the different compounds may be due to the formation of Schiff base/grafting of salicylaldehyde, spacial hindrance, hydrophobic force and $\pi$ - $\pi$ stacking.

\subsection{Catalytic Ability}

The catalytic oxidation of alkanes with $30 \% \mathrm{H}_{2} \mathrm{O}_{2}$ as oxidant under mild aerobic conditions is significantly a fascinating reaction, because the direct functionalisation of inactivated $-\mathrm{C}-\mathrm{H}$ bonds in saturated hydrocarbons usually requires drastic reaction conditions such as high temperature and pressure. Table 3 explains the conversion percentage of cyclohexane at room temperature and $70^{\circ} \mathrm{C}$. There is no product obtained at room temperature conditions which may be due to the non decomposing nature of $\mathrm{H}_{2} \mathrm{O}_{2}$ at room temperature. The results also explore that there is no evidence for the product without the catalyst and also without $\mathrm{H}_{2} \mathrm{O}_{2}$ even at $70^{\circ} \mathrm{C}$. According to the products obtained from the $\mathrm{GC}$ analyses, the first and slow step might be the formation of cyclohexanol and the second step may be the oxidation of cyclohexanol to cyclohexanone.

Complex 1 is the most efficient catalyst with the \% conversion of cyclohexane. The highest selectivity of the desired products was reached with complex 1. Very important point in the oxidation of cyclohexane is the reduction of $\mathrm{Cu}(\mathrm{II})$ to $\mathrm{Cu}(\mathrm{I})$ of the complexes. This reduction of $\mathrm{Cu}(\mathrm{II})$ facilitates the ligand around the metal ion.

\subsection{Catalytic Reusability}

The reusability of the catalyst is the very important one in the field of heterogeneous catalysis. To check the reusability of the complexes, complex 1 was selected. This complex 1 was investigated by separating through filtration after the first catalytic reaction was completed. This filtered catalyst was recovered by washing with solvent and dried under vacuum, then used in the second run by following the same reaction conditions. The catalytic run was repeated five times with the further addition of substrates in sufficient amount under the same reaction conditions. The nature and yield of the final products were comparable to that of the original one. The reusability of the catalyst, complex 1 was illustrated in Figure 6 for the five repeated cycles. It shows that catalytic efficacy did diminish significantly after fourth repeated run. The reason might be the poor chemical resistance and mechanical strength of chitosan bio polymeric backbone [35] which provides the heterogeneity to the complex.

\section{Conclusion}

Three new different $\mathrm{Cu}$ (II) mixed ligand complexes have synthesized and characterized. They were found to be air stable. Tetra coordinated square planar geometry were allotted to complexes 1 and 3 and penta coordinated square pyramidal geometry was assigned to complex 3 by the spectral evidences. Thermal stability of the complexes was found to be less than that of their Schiff base ligand, SC due to the change in stacking order. SEM images of the complexes displayed rough surface with some pores (active sites) compared to chitosan and its Schiff base, SC. This surface morphology changes with pores formation added the positive effects in catalytic reactions. The crystalline property of the compounds was explored by X-ray diffraction studies. The crystallinity of the analysed compounds was in the following order: chitosan $>$ 
Table 3. Conversion percentage of cyclohexane and selectivity of the products.

\begin{tabular}{ccccc}
\hline \multirow{2}{*}{ Conditions } & \multicolumn{3}{c}{ Conversion (\%) } & Selectivity (\%) \\
\cline { 2 - 5 } & $\mathrm{C} 1$ & $\mathrm{C} 2$ & $\mathrm{C} 3$ & $(\mathrm{C} 1 / \mathrm{C} 2 / \mathrm{C} 3)$ \\
\hline $\mathrm{A}$ & & & & \\
\hline B & & & & \\
\hline $\mathrm{C}$ & & & & \\
\hline $\mathrm{D}$ & 34 & 22 & 27 & $\begin{array}{c}\text { Cyclohexanol }(77 / 42 / 61) \\
\text { Cyclohexanone }(23 / 58 / 39)\end{array}$ \\
\hline
\end{tabular}

A: Without catalyst at room temperature and $70^{\circ} \mathrm{C}$; B: Without $\mathrm{H}_{2} \mathrm{O}_{2}$ at room temperature and $70^{\circ} \mathrm{C} ; \mathrm{C}$ : With catalyst and $\mathrm{H}_{2} \mathrm{O}_{2}$ at room temperature; D: With catalyst and $\mathrm{H}_{2} \mathrm{O}_{2}$ at $70^{\circ} \mathrm{C} ; \mathrm{C} 1$ : complex 1; C2: complex 2; $\mathrm{C} 3$ : complex 3 .

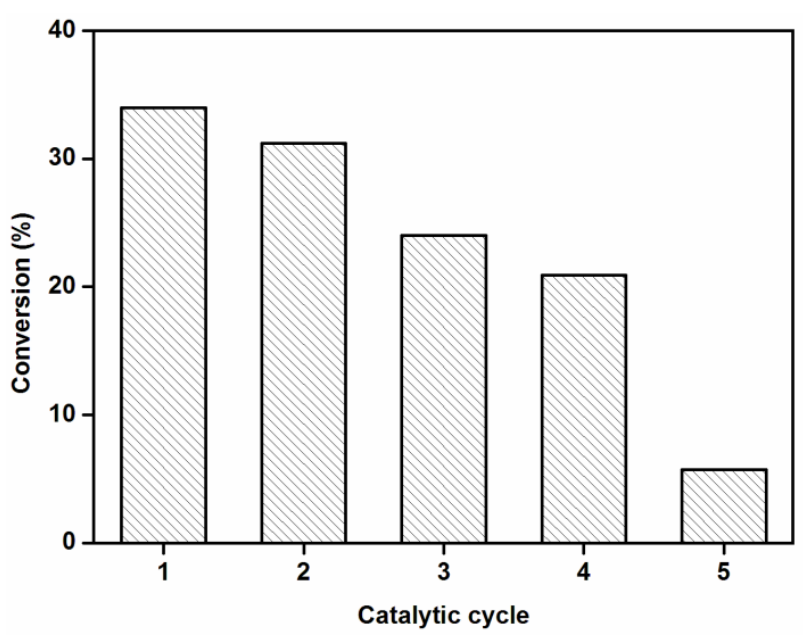

Figure 6. Catalytic reusability of complex 1.

SC $>$ complex $2>$ complex $1>$ complex 3 . Cyclohexane was oxidized into cyclohexanol and cyclohexanone by the complexes and complex 1 showed highest catalytic activity than other two complexes. Currently, we are analysing the effect of irradiation on the surface, structure and catalytic ability of these reported complexes.

\section{Acknowledgements}

The authors gratefully acknowledge the Department of Atomic Energy-Board of Research in Nuclear Sciences (DAE-BRNS), Mumbai, India for providing financial support to carry out this research work. The authors also thank the management of PSN College of Engineering and Technology, Tirunelveli-627 152, India for providing essential research facilities. XRD analysis facility provided by Department of Physics, Alagappa University, Karaikudi-630 003, India is gratefully acknowledged.

\section{REFERENCES}

[1] N. M. Alves and J. F. Mano, "Chitosan Derivatives Ob- tained by Chemical Modifications for Biomedical and Environmental Applications," International Journal of Biological Macromolecules, Vol. 43, No. 5, 2008, pp. 401414. doi:10.1016/j.ijbiomac.2008.09.007

[2] J. E. Santos, E. R. Dockal and E. T. G. Cavalheiro, "Synthesis and Characterization of Schiff Bases from Chitosan and Salicylaldehyde Derivatives," Carbohydrate Polymers, Vol. 60, No. 3, 2005, pp. 277-282. doi:10.1016/j.carbpol.2004.12.008

[3] M. N. V. R. Kumar, "A Review of Chitin and Chitosan Applications," Reactive and Functional Polymers, Vol. 46, No. 1, 2000, pp. 1-27. doi:10.1016/S1381-5148(00)00038-9

[4] R. A. A. Muzzarelli, "Chitin," Pergamon Press, Oxford, 1977, pp. 83-252.

[5] M. Rinaudo, "Chitin and Chitosan: Properties and Applications," Progress in Polymer Science, Vol. 31, No. 7, 2006, pp. 603-632. doi:10.1016/j.progpolymsci.2006.06.001

[6] C. Demetgul and S. Serin, "Synthesis and Characterization of a New Vic-Dioxime Derivative of Chitosan and Its Transition Metal Complexes," Carbohydrate Polymers, Vol. 72, No. 3, 2008, pp. 506-512. doi:10.1016/j.carbpol.2007.09.020

[7] V. V. Binsu, R .K. Nagarale, V. K. Shahi and P. K. Ghosh, "Studies on $N$-Methylene Phosphonic Chitosan/ Poly (Vinyl Alcohol) Composite Proton-Exchange Membrane," Reactive and Functional Polymers, Vol. 66, No. 12, 2006, pp. 1619-1629. doi:10.1016/j.reactfunctpolym.2006.06.003

[8] D. Britto and O. B. G. Assis, "A Novel Method For Obtaining A Quaternary Salt Of Chitosan," Carbohydrate Polymers, Vol. 69, No. 2, 2006, pp. 305-310. doi:10.1016/j.carbpol.2006.10.007

[9] K. V. H. Prashanth and R. N. Tharanathan, "Chitin/Chitosan: Modifications and Their Unlimited Application Potential-An Overview," Trends in Food Science \& Technology, Vol. 18, No.3, 2007, pp. 117-131. doi:10.1016/j.tifs.2006.10.022

[10] X. Jin, J. Wang and J. Bai, "Synthesis and Antimicrobial Activity of the Schiff Base from Chitosan and Citral," Carbohydrate Research, Vol. 344, No. 6, 2009, pp. 825829. doi:10.1016/j.carres.2009.01.022

[11] M. Monier, D. M. Ayad, Y. Wei and A. A. Sarhan, "Adsorption of $\mathrm{Cu}(\mathrm{II}), \mathrm{Co}(\mathrm{II})$, and $\mathrm{Ni}(\mathrm{II})$ Ions by Modified Magnetic Chitosan Chelating Resin," Journal of Hazardous Materials, Vol. 177, No. 1-3, 2010, pp. 962-970. doi:10.1016/j.jhazmat.2010.01.012

[12] L.-X. Wang, Z.-W. Wang, G.-S. Wang, X.-D. Lin and J.-G. Ren, "Catalytic Performance of Chitosan-Schiff Base Supported Pd/Co Bimetallic Catalyst for Acrylamide with Phenyl Halide," Polymers for Advanced Technologies, Vol. 21, No. 4, 2010, pp. 244-249.

[13] R. R. Mohamed and A. M. Fekry, "Antimicrobial and Anticorrosive Activity of Adsorbents Based on Chitosan Schiff's Base," International Journal of Electrochemical Science, Vol. 6, No. 7, 2011, pp. 2488-2508.

[14] J. M. Liu, W. Sun, S. Z. Zheng and C. G. Xia, "Efficient 
Synthesis of Oxazolidin-2-One via (Chitosan-Schiff Base) cobalt(II)-Catalyzed Oxidative Carbonylation of 2-Aminoalkan-1-Ols," Helvetica Chimica Acta, Vol. 90, No. 8, 2007, pp. 1593-1598. doi:10.1002/hlca.200790167

[15] R. M. Wang, N. P. He, P. F. Song, Y. F. He, L. Ding and Z. Q. Lei, "Preparation of Nano-Chitosan Schiff-Base Copper Complexes and Their Anticancer Activity," Polymers for Advanced Technologies, Vol. 20, No. 12, 2009, pp. 959-964. doi:10.1002/pat.1348

[16] U. Schuchardt, W. A. Carvalho and E. V. Spinacé, "Why is it Interesting to Study Cyclohexane Oxidation?" Synlett, Vol. 1993, No. 10, 1993, pp. 713-718.

[17] W. Kanjina and W. Trakarnpruk, "Oxidation of Cyclohexane and Ethyl Benzene by Hydrogen Peroxide over Co-Substituted Heteropolytungstate Catalyst," Journal of Metals, Materials and Minerals, Vol. 20, No. 2, 2010, pp. 29-34.

[18] I. R. Hammoumraoui, A. C. Braham, L. P. Roy and C. Kappenstein, "Catalytic Oxidation of Cyclohexane to Cyclohexanone and Cyclohexanol by Tert-Butyl Hydroperoxide over Pt/Oxide Catalysts," Bulletin of Material Science, Vol. 34, No. 5, 2011, pp. 1127-1135. doi:10.1007/s12034-011-0157-6

[19] T. F. Silva, G. S. Mishra, M. F. da Silva, R. Wanke, L. M. Martins and A. J. Pombeiro, "Cu ${ }^{\text {II }}$ Complexes Bearing the 2,2,2-Tris (1-Pyrazolyl) ethanol or 2,2,2-Tris (1-Pyrazolyl) ethyl Methanesulfonate Scorpionates. X-Ray Structural Characterization and Application in the Mild Catalytic Peroxidative Oxidation of Cyclohexane," Dalton Transactions, Vol. 2009, No. 42, 2009, pp. 9207-9215.

[20] S. M. Islam, A. S. Roy, P. Mondal, M. Mubarak, S. Mondal, D. Hossain, S. Banerjee and S. C. Santra, "Synthesis, Catalytic Oxidation and Antimicrobial Activity of Copper(II) Schiff Base Complex," Journal of Molecular Catalysis A: Chemical, Vol. 336, No. 1-2, 2011, pp. 106114. doi:10.1016/j.molcata.2011.01.006

[21] N. Raman, S. J. Raja, J. Joseph and J. D. Raja, "Synthesis, Spectral Characterization and DNA Cleavage Study of Heterocyclic Schiff Base Metal Complexes," Journal of Chilean Chemical Society, Vol. 52, No. 2, 2007, pp. 1138-1141.

[22] S. Mansouri, P. Lavigne, K. Corsi, M. Benderdour, E. Beaumont and J. C. Fernandes, "Chitosan-DNA Nanoparticles as Non-Viral Vectors in Gene Therapy: Strategies to Improve Transfection Efficacy," European Journal of Pharmaceutics and Biopharmaceutics, Vol. 57, No. 1, 2004, pp. 1-8. doi:10.1016/S0939-6411(03)00155-3

[23] F. Tian, Y. Liu, K. Hu and B. Zhao, "Study of the Depolymerization Behavior of Chitosan by Hydrogen Peroxide," Carbohydrate Polymers, Vol. 57, No. 1, 2004, pp. 31-37. doi:10.1016/j.carbpol.2004.03.016

[24] A. H. Al-kubaisi and K. Z. Ismail, "Nickel(II) and Palladium(II) Chelates of Dehydroacetic Acid Schiff Bases Derived from Thiosemicarbazide and Hydrazinecarbidithioate," Canadian Journal of Chemistry, Vol. 72, No. 8, 1994, pp. 1785-1788. doi:10.1139/v94-226

[25] N. Raman, A. Selvan and S. Sudharsan, "Metallation of
Ethylenediamine Based Schiff Base with Biologically Active $\mathrm{Cu}(\mathrm{II}), \mathrm{Ni}(\mathrm{II})$ and $\mathrm{Zn}(\mathrm{II})$ ions: Synthesis, Spectroscopic Characterization, Electrochemical Behaviour, DNA Binding, Photonuclease Activity and in Vitro Antimicrobial Efficacy," Spectrochimica Acta Part A: Molecular and Biomolecular Spectroscopy, Vol. 79, No. 5, 2011, pp. 873-883. doi:10.1016/j.saa.2011.03.017

[26] J. Ribas, C. Diaz, R. Costa, Y. Journaux, C. Mathoniere, O. Kahn and A. Gleizes, "Structure and Magnetic and Spectroscopic Properties of a Nickel(II)Copper(II)Nickel(II) Trinuclear Species," Inorganic Chemistry, Vol. 29, No. 11, 1990, pp. 2042-2047. doi:10.1021/ic00336a003

[27] S. L. Sun and A. Q. Wang, "Adsorption Properties Of Carboxymethyl-Chitosan and Cross-Linked Carboxymethyl-Chitosan Resin With $\mathrm{Cu}(\mathrm{II})$ as Template," Separation and Purification Technology, Vol. 49, No. 3, 2006, pp. 197-204. doi:10.1016/j.seppur.2005.09.013

[28] N. A. Anan, S. M. Hassan, E. M. Saad, I. S. Butler and S. I. Mostafa, "Preparation, Characterization and $\mathrm{pH}-$ Metric Measurements of 4-Hydroxysalicylidenechitosan SchiffBase Complexes of Fe(III), Co(II), Ni(II), Cu(II), Zn(II), $\mathrm{Ru}(\mathrm{III}), \mathrm{Rh}(\mathrm{III}), \mathrm{Pd}(\mathrm{II})$ and $\mathrm{Au}(\mathrm{III}), "$ Carbohydrate Research, Vol. 346, No. 6, 2011, pp. 775-793. doi:10.1016/j.carres.2011.01.014

[29] O. A. Monteiro Jr. and C. Airoldi, "Some Studies of Crosslinking Chitosan-Glutaraldehyde Interaction in a Homogeneous System," International Journal of Biological Macromolecules, Vol. 26, No. 2-3, 1999, pp. 119-128. doi:10.1016/S0141-8130(99)00068-9

[30] R. P. Dhakal, T. Oshima and Y. Baba, "Planarity- Recognition Enhancement Of $N$-(2-Pyridylmethyl)Chitosan By Imprinting Planar Metal Ions," Reactive and Functional Polymers, Vol. 68, No. 11, 2008, pp. 1549-1556. doi:10.1016/j.reactfunctpolym.2008.08.008

[31] G. A. Roberts, "Chitin Chemistry," Macmillian Press, London, 1992.

[32] H. Zhang, Y. M. Du, J. H. Yu, R. H. Huang and L. N. Zhang, "Preparation and Characterization of Chitosan/ Poly(Vinyl Alcohol) Blend Fibers," Journal of Applied Polymer Science, Vol. 80, No. 13, 2001, pp. 2558-2565. doi:10.1002/app.1365

[33] T. F. Jiao, J. Zhou, J. X. Zhou, L. H. Gao, Y. Y. Xing and X. H. Li, "Synthesis and Characterization of ChitosanBased Schiff Base Compounds with Aromatic Substituent Groups," Iranian Polymer Journal, Vol. 20, No. 2, 2011, pp. 123-136.

[34] Y. Q. Zhang, C. H. Xue, Y. Xue, R. C. Gao and X. L. Zhang, "Determination of the Degree of Deacetylation of Chitin and Chitosan by X-Ray Powder Diffraction," Carbohydrate Research, Vol. 340, No. 11, 2005, pp. 19141917. doi:10.1016/j.carres.2005.05.005

[35] K. Martina, S. E. S. Leonhardt, B. Ondruschka, M. Curini, A. Binello and G. Cravotto, "In Situ Cross-Linked Chitosan $\mathrm{Cu}(\mathrm{I})$ or Pd(II) Complexes as a Versatile, EcoFriendly Recyclable Solid Catalyst," Journal of Molecular Catalysis A: Chemical, Vol. 334, No. 1-2, 2011, pp. 60-64. doi:10.1016/j.molcata.2010.10.024 